\title{
A Point Frame for Circular Plots in Southern Forest-Ranges
}

\author{
R.L. BAKER AND C.E. THOMAS
}

\begin{abstract}
A point frame has been modified to allow for plant cover estimates to a $152 \mathrm{~cm}$ height. Construction of a third crossmember that can be added to a $76-\mathrm{cm}$ tall polnt frame allows sampling pins to be projected both upward and downward. Spacings between pins were changed to produce equal sampling a reas while sampling circular plots. This design was tested with a miniature point frame on artificial plant populations and was shown to measure within $\pm 5 \%$ of actual cover values.
\end{abstract}

The point frame, widely used in range ecological work, is normally placed at selected field points or moved along a transect. Point frames have been used to measure plant height (Heady 1957), insect damage (Nerney 1960), leaf area (Warren-Wilson 1963), basal cover (Fisser and Van Dyne 1966), foliar cover, frequency, herbage production and species composition (Hughes 1962), and to determine plant density in rectangular quadrats (Ellison 1942).

The basic point frame with its sampling precision (Schultz et al. 1961, Hutchings and Pase 1963, Fisser and Van Dyne 1966) is easily modified and retains its accuracy and usefulness with design modifications. Point frames have been constructed of wood, steel, and aluminum. Modifications are normally made for specific purposes such as the sampling of a vegetation type, the increase of accuracy, or the ease of sampling (Nerney 1960, Long et al. 1972, Sharrow and Tober 1979).

Foliar cover of herbaceous and woody vegetation is important in determining understory vegetation production and composition in southern forests (Pearson and Sternitzke 1974). The point frame can be used to determine foliar cover and botanical composition accurately; therefore, it was selected for use in training and checking ocular estimates of plant cover on $1-\mathrm{m}^{2}$ circular plots by Forest Service Renewable Resource Evaluation field personnel during extensive forest resource surveys in midsouth forests. (Foliar cover of herbage can be used to estimate herbage production from established foliar cover-herbage production relationships). We will discuss how modifications in frame height and pin spacing can allow the point frame to be used in small, circular plot sampling.

\section{Frame Dimensions}

On southern forest-range, herbage and browse foliage occurs throughout the $152 \mathrm{~cm}$ sampling height. Therefore we viewed our circular, $1-\mathrm{m}^{2}$ sample plot as a cylinder, $152 \mathrm{~cm}$ high and $1 \mathrm{~m}^{2}$ in cross section area $(113 \mathrm{~cm}$ diameter); the point frame must be able to sample plant foliar cover from the entire volume of the cylinder $\left(1.52 \mathrm{~m}^{3}\right)$. Frame width is $133 \mathrm{~cm}$, which allows each leg to cxtend $10 \mathrm{~cm}$ past the plot boundary and not influence vegetation along the plot perimeter (Fig. 1). The frame stands vertically, supported by 2 spike feet pressed into the soil.

The main point frame height is $76 \mathrm{~cm}$, one-half of the $152-\mathrm{cm}$ sampling height investigated, with crossmembers at 38 and $76 \mathrm{~cm}$

\footnotetext{
Authors are range scientist and research forester, Southern Forest Experiment Station. 701 Loyola. New Orleans. La. 70113.

Appreciation is expressed to the Tulane University Delta Regional Primate Research Center for the use of laboratory equipment.

Manuscript received July 23,1981 .
}

Complete step-by-step plans and instructions for this frame are available from the senior author.

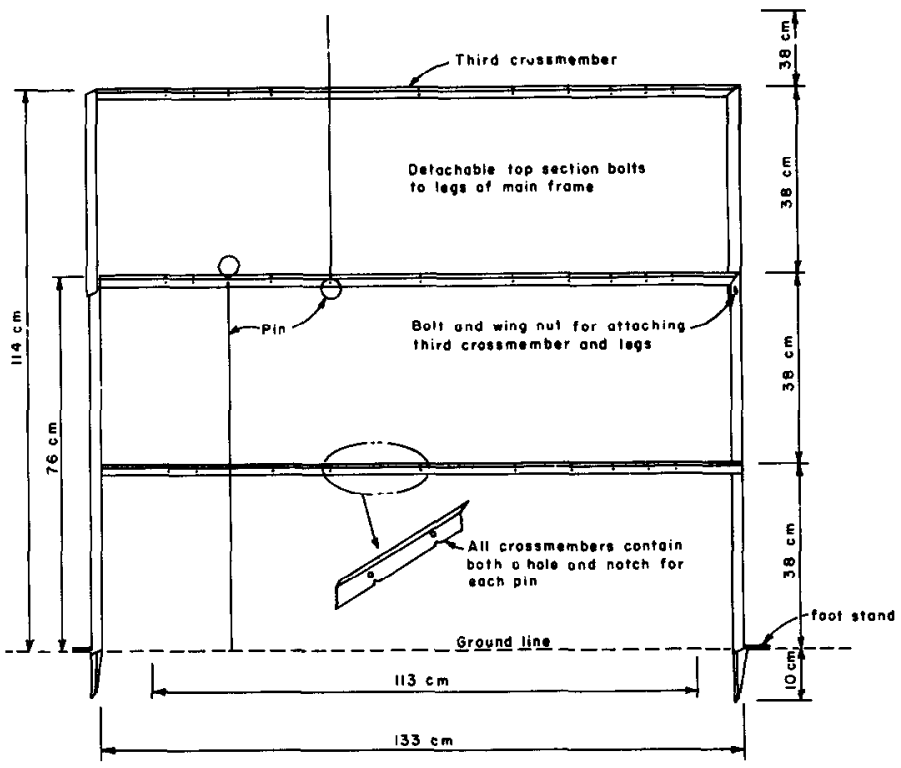

Fig. 1. Diagram of the point frame showing third crossmember and pin spacings.

(Fig. 1). Crossmembers have holes and notches for pin guides (Rader and Ratliff 1962). Only between 0 and $38 \mathrm{~cm}$ are there 2 guides per pin to guide pins straight. A third crossmember $(133 \mathrm{~cm})$ was constructed with legs about $43 \mathrm{~cm}$ long that are bolted to the legs of the main frame several centimeters below the second crossmember at $76 \mathrm{~cm}$. This third crossmember that was added to the basic $76-\mathrm{cm}$ tall main frame raises total frame height to $114 \mathrm{~cm}$ or three-quarters of the total $152-\mathrm{cm}$ sampling height and provides a second guide for pins sampling the $38-$ to $76-\mathrm{cm}$ region. The third crossmember also allows the a rea from 76 to $152 \mathrm{~cm}$ to be sampled by projecting the pins upward through the second and third crossmembers (Fig. 1). Pin length without the loop handle is $76 \mathrm{~cm}$; so when the pin is projected upward and the handle reaches the crossmember at $76 \mathrm{~cm}$, the pin point is at the $152 \mathrm{~cm}$ height.

Pins of $3.2 \mathrm{~mm}$ ( $1 / 8 \mathrm{inch}$ ) bronze welding rod a re fashioned with a loop at one end; the other end is sharpened. Steel rod pins would hold straightness longer but in the humid South they would also rust quickly. Pins may become slightly bent during use, but the data variation associated with failure of pins to follow a plumb line, in our judgment, is acceptable because of the objectivity associated with pin hits and relationship to vegetation on the ground. There is some disturbance of shrub foliage because of frame height and size, but this too is judged to be acceptable since cover can be sampled up to a $152 \mathrm{~cm}$ height.

Our frame is constructed of $2.54-\mathrm{cm}$ ( 1 inch) angle aluminum. This frame is held together by $4.8-\mathrm{mm}$ ( $3 / 16$ inch) stove bolts and can be dismantled for transporting or shipping if necessary. Time required for manufacturing the aluminum frame, without pins, was about 3 man-hours.

\section{Pin Spacing}

Pins normally are spaced equally in point frames, but in sam- 


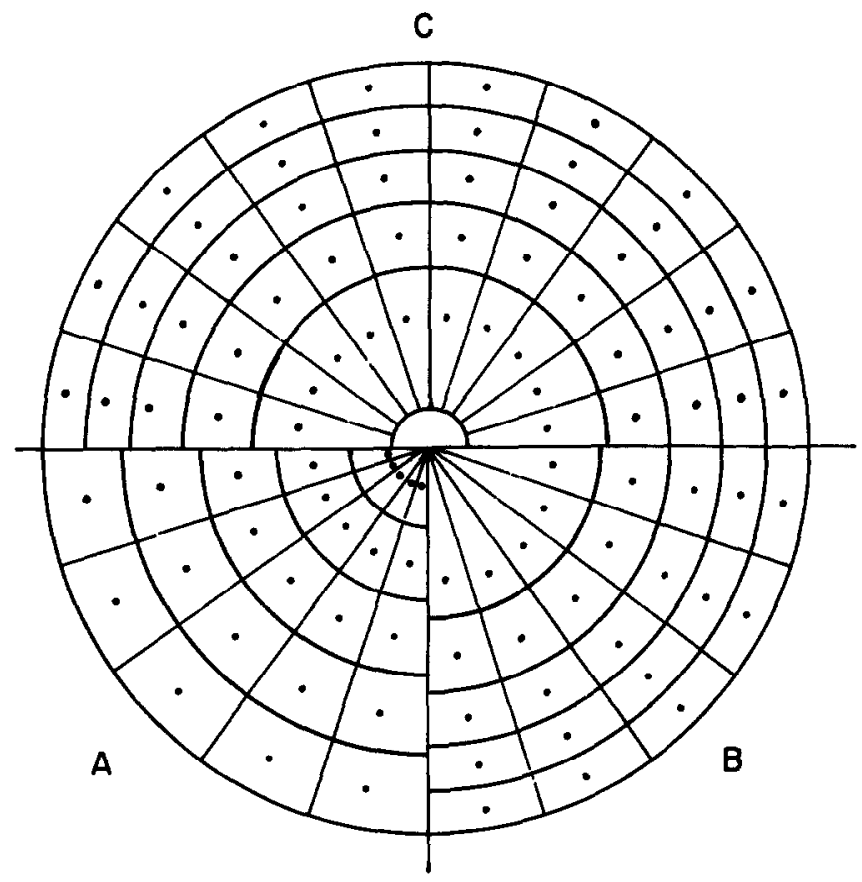

Fig. 2. Composite illustration of alternative sample point distributions within a circular plot: (a) equally spaced radial points, unequal areas; (b) quadratic spacing, no central point, equal areas; (c) quadratic spacing with central point, equal areas.

pling circular plots, the central portion of the plot is over-sampled at the expense of the outer portion (Gaiser 1951, Van Dyne 1965) (Fig. 2a). A circular point frame used on circular microplots sampled from the entire microplot at one placement and did not have to be moved (Morris 1973); therefore, all areas sampled by a pin were of equal size and shape. Our frame design for this study began with a 10 -pin frame, and 100 pin readings per plot were required. A circular, conceptual sampling plot was divided into 5 concentric circular regions, each equal to the central circle in area (Fig. 2b). The plot was subdivided by 20 equally spaced radii $18^{\circ}$ apart resulting in 100 sampling areas. Pin locations in the sampling frame were obtained using quadratic mean radii. This design corrects $\mathrm{fc}_{1}$ the usual sample concentration at or near plot center, which is obtained using equal spacing distance between points on radii (Van Dyne 1960, 1965) (Fig. 2b).

Because of the apparent sampling void in the center of the circle (Fig $2 b$ ), an 11 th point is located at the center of the frame, which is read only once (Fig. 2c). Thus, 101 pins are read per plot and slight differences in sampling percentages for each pin, 1/100 vs $1 / 101$, are easily handled by modern calculators and computers. Side lengths of each of the 100 sampling areas differ slightly in each circular ring but a re equal in a rea (Fig. 2c). Pin holes and notches were made $0,19,31,40,47$, and $53 \mathrm{~cm}$ from the center of the frame.

\section{Design Testing}

Ideally, design modifications made to a point frame should have no adverse effect on accuracy. The canopy cover of artificial populations was sampled with a miniature point frame we constructed to test our pin spacing for circular plots (Schultz et al. 1961). Artificial plant populations were constructed on miniature, circular, paper test plots instead of constructing a large population board. The miniature point frame and test lots were made to a scale of $1 \mathrm{~mm}=1 \mathrm{~cm}$ and $1 \mathrm{~mm}^{2}=1 \mathrm{~cm}^{2}$. In order to determine plant cover parameters of the population within each plot, the simulated plants were all kept circular and canopy cover was measured instead of foliar cover. Canopy cover is the percentage of ground included in a vertical projection of imaginary polygons drawn about the total natural spread of foliage, while foliar cover is the sum of shadows that would be cast by leaves and stems (Dauben- mire 1968). To simulate "natural" conditions, the decision was made that no "plant" would have a radius greater than that of the plot, and that the total "plant" did not have to be located within the plot boundary (Fig. 3).

Understory vegetation data that had been collected on $1-m^{2}$ circular plots in Tennessee forests were used to determine the mean and standard deviation for the plant size and number of plants in each of 30 test plots. Plant size, number, and location were selected using an elect ronic calculator random number generation program (Gaiser 1951, Van Dyne 1960). Size and number of plants were considered to be distributed normally around the calculated mean while location in the plot was considered to be randomly distributed. Plant location was selected, first, by determining the compass bearing of a plant in the plot $\left(1-360^{\circ}\right)$ and, secondly, the radius distance of the plant center from the test plot center $(0-56.5 \mathrm{~mm})$. Plant size was then determined and "plants"(discs) were drawn on test plots with a compass. The process was repeated for every "plant" occurring in each test plot.

Thirty test plots were constructed on paper (Fig. 3). Number of plants ranged from 3 to 13 per plot; individual "plant" size ranged from less than $1 \%$ to $43 \%$ of the test plot cover. The miniature point framc was used to determine percent canopy cover by "plants"; 101 points were read on each test plot. Total plot canopy cover was determined, so areas of overlapping plant canopies were counted only once. Each test plot was read twice; the second time frame placement on the plot circumference was $9^{\circ}$ away from initial readings, and any test plot with point readings differing by more than $2 \%$ was resampled to verify results.

Point frame readings were compared with results from determining area by a dot grid and by weight. A dot grid was constructed with 4 dots representing $1 \%$ of the test plot cover. "Plants" (discs) with known areas of $1 \%$ to $40 \%$ were read twice with the dot grid to test dot grid accuracy, and the counts were never more than $\pm 0.75 \%$ different. Each of the 30 test plots was sampled twice with the dot grid; and if percent canopy cover from test plot dot counts differed by more than $\pm 2 \%$ or was more than $\pm 3 \%$ different from point frame canopy cover readings, recounts were made to verify results. "Plants" were then cut from each test plot and paper "plants" from each plot were weighed on a Mettler H54-AR analytical balance to the nearest 0.01 milligram. "Plants" (discs) of known area were cut from paper and weighed resulting in a standard curve to determine cover of the 30 test plot samples (Fig. 4). Samples of 26 combinations of known circular area representing 1 to $100 \%$ of test plot cover were weighed and replicated independently, and if weights differed more than \pm 1.00 milligram, those

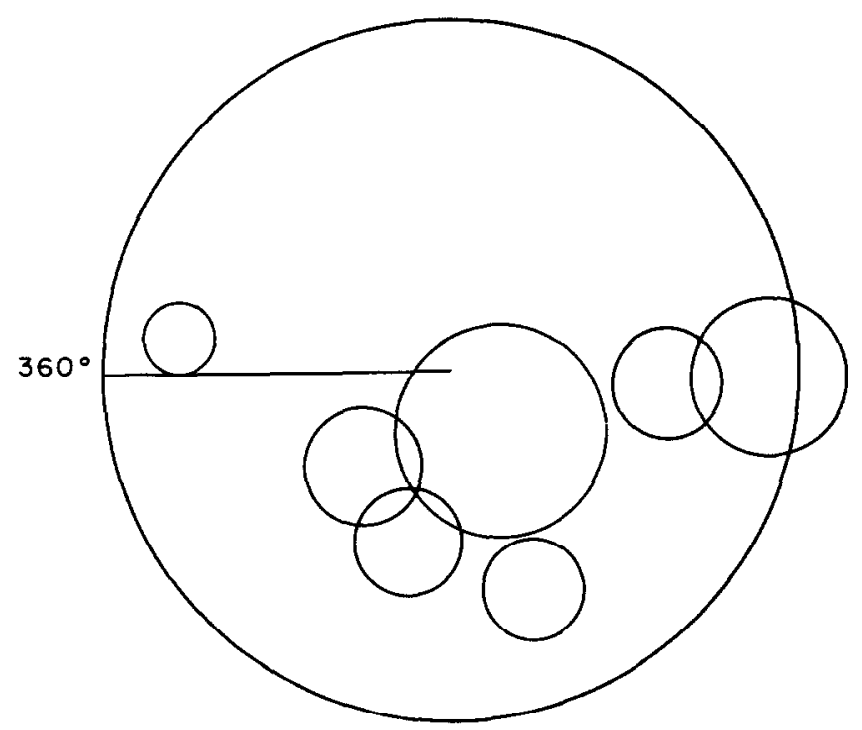

Fig. 3. Representative sample plot with artificial plants shown as circles. 
samples were reweighed. Linear regression was used to develop a standard curve for cover from the known area weights; $\boldsymbol{R}^{2}$ for the standard curve was .999 . The regression equation was used to determine percent cover of the 30 test plot samples (Fig. 4). Weights were the most accurate method of determining cover.

Canopy cover from miniature point frame counts on the 30 test plots was compared to test plot canopy cover determined from disc weights using a chi square test for accuracy (Freese 1960). Canopy cover readings from the miniature point frame with modified pin spacings were within $\pm 5 \%$ of the actual cover (as measured by weight) $95 \%$ of the time. Cover determined from dot grid counts was within $\pm 4 \%$ of the actual cover (weight) $95 \%$ of the time. Test plots with larger "plants" ( 15 to $25 \%$ cover) near the plot center or with small, dispersed "plants $(\leq 3 \%$ cover) representing less than $15 \%$ of the plot cover were the most difficult plots for the miniature point frame to accurately sample because of pin spacing. Increasing the number of pins on the frame would probably increase the accuracy but it would also increase the time required for sampling. Further research could be done to determine the total number of pin readings necessary for different levels of reliability within circular plots.

\section{Application}

Addition of a third crossmember to a point frame to allow upward projection of pins to sample vegetation cover to a $152 \mathrm{~cm}$ height with little additional disturbance to the vegetation produces additional flexibility of the point frame in southern forest-range. The point frame is initially placed at a randomly selected started point along the circumference of the $1-\mathrm{m}^{2}$ circular plot. The subsequent 9 frame placements are made about $18 \mathrm{~cm}$ apart. The third crossmember can easily be attached or detached, depending upon vegetation height being sampled.

Equipment weight and builkiness are important considerations in southern forests when sampling equipment must be carried long distances or through dense understory to reach the sample location. Thus, a light-weight aluminum point frame is preferred and can be entirely dismantled for transport or reconstructed within 5 minutes using only a screwdriver and wrench. The point frame design can easily be used with larger or smaller circular plots but new pin locations must be calculated. If plot diameter reaches such a length that the required size point frame becomes unwieldy, then a shorter frame the length of the plot radius can be used for sampling. These changes allow an increased use of the point frame for plant ecological surveys in southern forest-range.

\section{Literature Cited}

Daubenmire, R. 1968. Plant communities. Harper and Row, Publ. N.Y. Ellison, L. 1942. A comparison of methods of quadratting short-grass vegetation. J. Agr. Res. 64:595-614.

Fisser, H.G., and G.M. Van Dyne. 1966. Influence of number and spacing of points on accuracy and precision of basal cover estimates. J. Range Manage. 19:205-211.

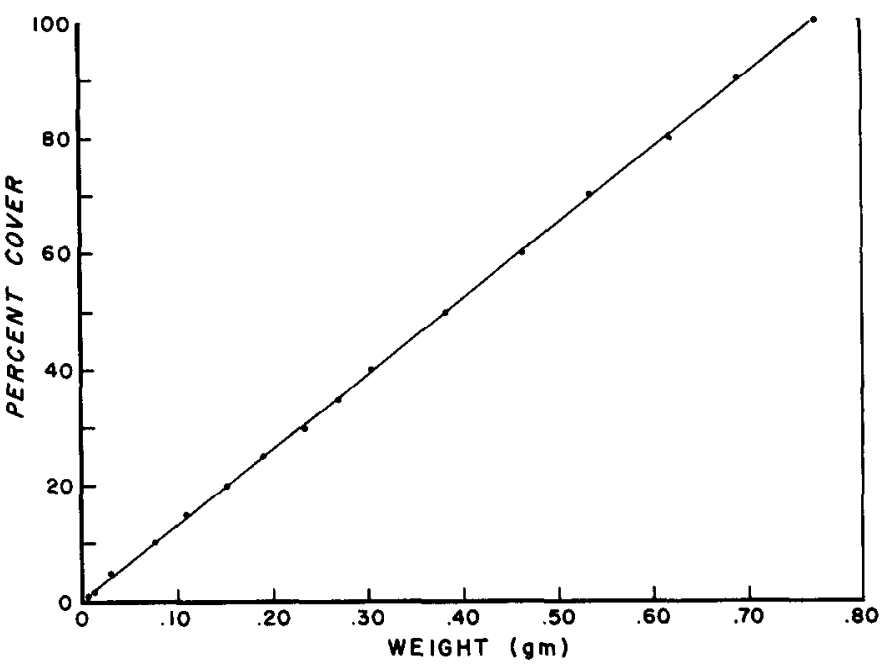

Fig. 4. Standard curve of area weights showing weights of known area circles.

Freese, F. 1960. Testing accuracy. Forest Sci. 6:139-145.

Gaiser, R.N. 1951. Random sampling within circular plots by means of polar coordinates. J. Forest. 49:916-917.

Heady, H.F. 1957. The measurement and value of plant height in the study of herbaceous vegetation. Ecology 38:313-320.

Hughes, E.E. 1962. Estimating herbage production using inclined point frame. J. Range Manage. 15:323-325.

Hutchings, S.S., and C.P. Pase. 1963. Measurement of plant cover-basal, crown, leaf area. P. 22-30 In: Range research methods. USDA FS Misc. Pub. no. 940.

Long, G.A., P.S. Poissonet, J.A. Poissonet, P.M. Daget, and M.P. Godron. 1972. Improved needle point frames for exact line transects. J. Range Manage. 25:228-229.

Morris, M.J. 1973. Estimating understory plant cover with rated microplots. USDA FS Res. Pap. RM-104.

Nerney, N.J. 1960. A modification for the point-frame method of sampling range vegetation. J. Range Manage. 13:261-262.

Pearson, H.A., and H.S. Sternitzke. 1974. Forest-range inventory: a multiple-use survey. J. Range Manage. 27:404-407.

Rader, L., and R.D. Ratlifi. 1962. A new idea in point frames. J. Range Manage. 15:182-183.

Schultz, A.M., R.P. Gibbens, and L. DeBano. 1961. Artificial populations for teaching and testing range techniques. J. Range Manage. 14:236-242.

Sharrow, S.H., and D.A. Tober. 1979. A simple, lightweight point frame. J. Range Manage. 32:75-76.

Van Dyne, G.M. 1960. A method for random location of sample units in range investigations. J. Range Manage. 13:152-153.

Van Dyne, G.M. 1965. A further note of random locations for sample units in circular plots. J. Range Manage. 18:150-151.

Warren-Wilson, J. 1963. Errors resulting from thickness of point quadrats. Aust. J. Bot. 11:178-188. 